\title{
The Reality of Education of Children with Autism in Mainstream 9-Year Schools in Albania
}

Florian Kulla1

\author{
Phd. Robert Gjedia ${ }^{2}$ \\ ${ }^{1}$ Phd Candidate, Psychology Department, University of Tirana, Tirana, Albania \\ 2University "Marin Barleti"Tirana, Albania \\ Email: floriankulla@gmail.com
}

Doi:10.5901/ajis.2015.v4n2s2p52

\section{Abstract}

\begin{abstract}
Although inclusive education for students with disabilities has been mentioned for several years in Albania, it has just started to be applied. A considerable number of studies show that despite the fact that the legislation regarding this group of children resembles that of the highest international standard, in reality, education for these children is difficult. This study focuses on a group of children with disabilities that face the highest level of difficulties in mainstream 9-year schools. A few studies show that the group facing more difficulties is that of children with autism and intellectual disabilities. In this paper, the methodology used was the analysis of secondary data from a research on the current situation of the education of children with disabilities in Albania, conducted by the author himself. This explorative study brings to the limelight the difficult reality and the many barriers that autistic children face during preschool and primary school. Furthermore, the study aims to provide a more holistic and concise view of the reality of these children in mainstream 9-year schools. Given the number of these qualitative and quantitative findings, the study provides a large number of recommendations for education in the central, regional and school levels.
\end{abstract}

Keywords: autism; inclusive education; disabilities; mainstream schools.

\section{Introduction}

The word autism originates from ancient Greek in which the word autos means self (Weiss \& Harris, 2001). Itard was the first to describe in a detailed manner, Victor's case (an autistic child), and hence become well-known for the precise description of the main symptoms of autism. Leo Kanner was the first to identify this disorder (Kanner, 1943). Surprisingly, in the same year, Hans Asperger (1991) identified another group of childhood development disorders that are now known as "the Asperger Syndrome".

Since the first time Kanner and Asperger identified and used this term (at the beginning of the 40's), the group of behavioral symptoms under autism has become wider. In the recent years, Autism Spectrum Disorders (ASD) is the most commonly diagnosed among childhood development disorders. Disorders of this spectrum affect children of all countries, ethnicities and social levels and they do not have cultural barriers (Center for Disease Control 2010). Even the latest version of Diagnostic and Statistical Manual of Mental Disorders (DSM) reflects several important changes/differences compared to the earlier version. According to DSM V, some of the features of Autism Spectrum Disorders are delayed or atypical development of communication skills. Furthermore, DSM-V has divided ASDs in three levels of functioning, based on the independent need for support and services including:

1. Those who seek help (high functioning),

2. Those who seek basic help (medium functioning) and

3. Those who seek more basic help (low functioning) (APA 2012).

According to DSM-V, Autism Spectrum Disorders are marked by deficiencies, retardation or atypical development of communication, social interaction and interactive skills, as well as by patterns of repetitive, confined and stereotypical behavior and activities (American Association of Psychiatry 2012).

In the last decades, the number of children diagnosed with disorders of this spectrum has increased significantly (Rice et al., 2010). A recent evaluation conducted in the United States, has shown that 1 in 88 individuals is diagnosed with this spectrum of disorders (Center of Disease Control 2012). This prevalence, as reported in 2012, shows an increase of $23 \%$ compared to a report of 2007 from the same research institution. 
In Albania, there are no precise data regarding the number of children with autism yet Como, 2011; Malile, 2007; $\mathrm{MSH}, 2013)$. There are several reasons for this lack of data, such as identification difficulties, difficulties when it comes to gathering statistical data, lack of coordination between institutions etc.

The very few existing data regarding the category of individuals with disabilities are very contradictory. According to statistics of the Ministry of Labor, Social Affairs and Equal Opportunities (2013), the number of children that received financial assistance in 2012 was 535 individuals. Other data from the Ministry of Education show that in the public schools of the country, the number of children with autism in compulsory education is 174 children. Besides that, other researchers assume that chances are high that the number of children with autism in Albania is the same as in other countries (Çomo 2011).

Despite the increasing number of autistic children in mainstream schools, studies show that the reality of education for students with autism is very difficult. (Save the Children 2012).

Even though main factors that impact the improvement of the quality of education for this group of children are given importance, the actual number of studies in this field is very scarce. This paper highlights the reality of autistic children in public schools across the country.

This study is explorative in its type. It aims to provide a bigger and more concise view of the reality of these children in the mainstream 9-year schools. This work is based on secondary data from a wider research conducted by the author regarding the actual situation of education for children with learning difficulties of all categories. Apart from the above mentioned material, the author has conducted interviews and created focus groups with a number of key players, in order to update the statistical data of the study and bring an update of the issues of his previous study.

To gather the necessary data for this study, the author has used a secondary data analysis method from another study that was recently completed on the situation of education of children with learning difficulties of all categories, in the country. The original study uses a combination of quantitative and qualitative methods.

Several quantitative and qualitative instruments have been used in this study, namely, two semi-structured questionnaires, numerous interviews and focus groups with key players.

Study sample. A considerable number of people were part of the study. The first structured questionnaire was distributed to all the REDs/EOs (Regional Education Departments) of the country. The second questionnaire was distributed to all specials schools of the country. To sample the focus groups for a better representation of the data, the author has used the Broad Involvement Design sampling technique. Principals, teachers, students and parents all were participants of the focus groups.

\section{Main Findings}

\subsection{Statistical findings}

According to the data gathered from the questionnaires, the number of autistic children in kindergartens and public 9-year schools is 164 , in other words $10 \%$ of children with learning difficulties can be found in public schools. This number does not compare to the number of autistic children as recognized by the Ministry of Social Welfare and Youth.



Chart 1: Number/percentage of children with learning difficulties of different categories in kindergartens and 9-year schools.

\subsection{Findings regarding barriers of children with autism in mainstream schools}

By combining quantitative and qualitative instruments it has been possible to obtain a considerable number of findings 
related to the barriers of children with learning difficulties in compulsory education. Autistic children, similarly to all children with learning difficulties, face and are hindered by a considerable number of barriers. These barriers can be structural, pedagogical, conceptual, professional, financial and behavioral. The group of autistic children faces specific barriers at a different level, when compared to other children with learning difficulties.

The first group of barriers for these children is related to the infrastructure and physical environment in the school. The schools have not gone through any changes that would help to welcome and increase the participation of autistic children. For most principals, the adjustment of the infrastructure means installing ramps on the ground floors. According to data gathered from the focus groups, for most principals and school staff, rearrangement of the environment to suit the needs of autistic children, means putting them in separate classrooms or in playrooms to calm them down, without being able to identify the necessary measures for the inclusion of children with autism.

Another barrier identified in this category, is the high number of children in a class, especially in urban areas. Furthermore, this number does not decrease even when an autistic child is part of the class. There are no learning tools for this group of children or the existing tools do not meet their special needs.

Very often, the work done for autistic children is not documented. In most cases, their individual plans do not meet the real needs of students with autism. Individual Education Plans, in most cases are written the by teacher and are not built by a specialized team that is capable of such task. Only in a few cases, do parents send their autistic child to a specialized center and based on the evaluations of the experts, real learning and development objectives are set for these children. Teachers say that, it is impossible for them to work independently with autistic children.

One the most significant difficulties that teachers faces with this group of children, is handling their behavior. In most regions there are no specialists to instruct the teachers on how to handle the behavior of these children.

Autistic children are the most stigmatized and discriminated group of children. They face continuous verbal abuse and very often are given derogatory names.

School staff is not informed and lacks knowledge when it comes to working with autistic children. Trainings were mainly held to raise awareness, and only in a few cases they were related to this group of children.

The whole experience of children with autism in mainstream schools is full of unexpected events, mainly because the schools do not have clear plans, procedures, structures and services to help the inclusion of these children.

\section{Recommendations}

The situation portrayed in this research shows the need for immediate measures from the local and central authorities, to improve as soon as possible the reality of children with autism in mainstream schools, in order to guarantee their right to quality education as basic right of every child.

Some of the main recommendations chosen from this research for the improvement of the situation of children with autism in 9-year schools are:

1. The need for infrastructure improvement in kindergartens and schools to enable the access of children with autism. To make sure that autistic children and all other children have access to and are welcomed by all the environments.

2. Appointing assistant teachers especially for this type of learning difficulty, in order to increase their participation in schools and to apply properly the Individual Education Plans.

3. Evaluation, training and support to school staff dealing with this group of children

4. The need to strengthen the role of school boards and the newly appointed ones within the Regional Education Authorities in order to build and perform real plans and individual goals

5. To ensure that the school environment is friendly and the teachers are understanding and supportive to these children.

\section{References}

American Psychiatric Association. (2004). Diagnostic and Statistical Manual of Mental Disorders, 4th Edition, Text Revision, (DSM-IV TR). Washington DC:

Atwood, T. (2000). Strategies to improve the social integration of children with Asperger Syndrome Autism: The International Journal of Research and Practice, 4(1), 85-100.

Bellini, C. (2002). Social abilities of children with autism spectrum disorders Journal of Applied Behavior Analysis, 58(2), $483-493$.

Booth, Tony and Mel Ainscow, Index for Inclusion: Developing Learning and Participation in Schools, CSIE, Bristol, revised edition 2002.

Closs, A., Nano, V. dhe Ikonomi, E. "I am like you" Save the Children. Tirana, 2003 
Cooper, J. O., Heron, T. E., \& Heward, W. L. (1987). Applied behavior analysis. New York, NY: Macmillan.

Mesibov, G. B. (1992). Treatment issues with high functioning adolescents and adults with autism. In E. Schopler \& G. B. Mesibov (Eds.), High functioning individuals with autism (pp. 143-155). New York, NY: Plenum Press.

Save the Children Albania "Inclusive education in Albania" An analytical study 2013

Siegel, B. (1996). The world of the autistic child: Understanding and treating autistic spectrum disorders. Neë York, NY: Oxford University Press.

UNICEF, Innocenti Research Centre (2005). Children and disability in transition in CEE/CIS and Baltic states.

Zela Koka, MA. Valentina Haxhiymeri, PhD. Marita Nika Flagler, Fatmir Bezati "The effective implementation of the legal framework guaranteeing the education of disabled children under the inclusive education" 